HNF-SP-0839

Revision 2

UC-600

\title{
Maintenance Implementation Plan for the Fast Flux Test Facility
}

\author{
J. A. Boyd \\ M. F. Duffield \\ B\&W Hanford Company \\ Date Published \\ January 1997
}

Prepared for the U.S. Department of Energy

Assistant Secretary for Environmental Management

Project Hanford Management Contractor for the

U.S. Department of Energy under Contract DE-ACO6-96RL13200

Approved for public release; distribution is unlimited 
LECAL DHSCLAMER

This report was prepared as an account of work sponsored by an agency of the United States Government. Neither the United States Govemment nor any agency thereof, nor any of their employees, nor any of their contractors, subcontrectors or their employees, makes any werranty, express or implied, or essumes any legal liebility or responsibility for the eccuracy, completeness, or any third party's use or the results of such use of any information, epparatus, product, or process disclosed, or represents that its use would not infringe privately owned rights. Reference herein to any specific cormmercial product, process, or service by trade name, trademark, mamufacturer, or otherwise, does not necessarily constitute or imply its endorsement, recommendetion, or favoring by the United States Government or any agency thereof or its contractors or aubcontractors. The views and opinions of authors expressed herein do not necessarily state or reflect those of the United States Government or any agency thereof.

This report has been reproduced from the best available copy. Available in paper copy and microfiche.

Available to the U.S. Department of Energy

and its contractors from

U.S. Department of Energy

Office of Scientific and Technical information (OST)

P.O. Box 62

Oak Ridge, TN 37831

(615) 576-8401

Printed in the United Stetes of Anorice

DISCLM-3.CHP (1-91) 


\section{RELEASE AUTHORIZATION}

Document Number: HNF-SP-0839, Rev. 2

Document Title: Maintenance Implementation Plan for the Fast Flux Test Facility

Release Date: $\quad 1 / 30 / 97$

This document was reviewed following the procedures described in WHC-CM-3-4 and is:

APPROVED FOR PUBLIC RELEASE

WHC Information Release Administration Specialist:

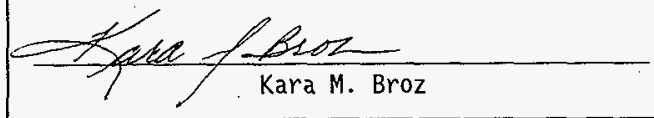




$$
\text { HNF-SP-0839, Rev. } 02
$$

Document Title: Plan for Implementation of Department of Energy 4330.4B for FFTF

Prepared by: $\frac{72.7 .10 \text { M.F. Duffels, Manager }}{\text { FFTF Maintenance Support }}$

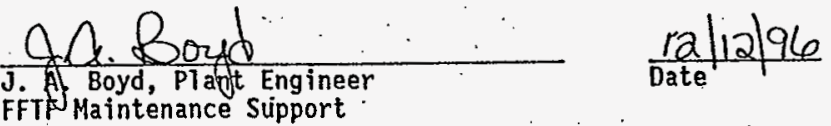

Approved by:
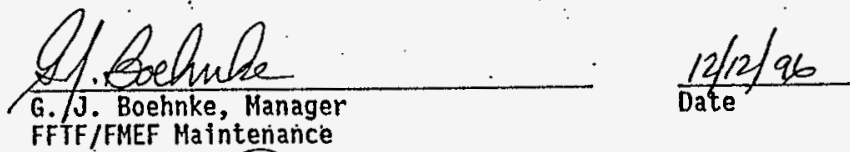

Approved by:

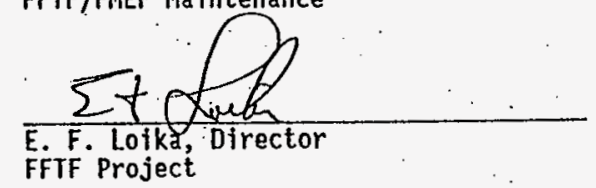

$$
\frac{12 / 12 / 96}{\text { Date }}
$$

ii j 
HNF-SP-0839, Rev. 02

CONTENTS

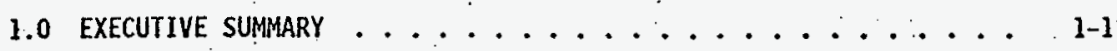

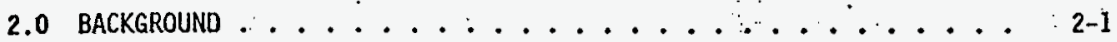

3.0 U.S. DEPARTMENT OF ENERGY 4330.4 B REQUIREMENTS ......... 3-1

3.1 MAINTENANCE PROGRAM SCOPE ...................... 3-1

3.2 MAINTENANCE PROGRAM REQUIREMENTS $\vdots \vdots \vdots \vdots \vdots \vdots \vdots 1$

3.3 SELF-ASSESSMENT PROGRAM . ...........

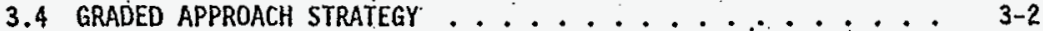

3.4 .1 0verall Strategy and Basis .......... 3-2

3.4.2 Strategy for Safety Related Items ....... 3-2

4.0 U.S. DEPARTMENT OF ENERGY 4330.48 CHAPTER II RËQUIREMENTS . . . . 4-1

4.1 MAINTENANCE ORGANIZATION ANO ADMINISTRATION ...... 4-1

4.2 TRAINING AND QUALIFICATION OF MAINTENANCE PERSONNEL .... 4-4

4.3 MAINTENANCE FACILITIIES, EQUIPMENT, AND TOOLS ....... 4-7

4.4 TYPES OF MAINTENANCE . . . . . . . . . . . 4-8

4.5 MAINTENANCE PROCEOURES ................ 4-11

4.6 PLANMING, SCHEDULING, AND CCORDINATION OF MAINTENANCE :. 4-14

4.7 CONTROL OF MAINTENANCE ACTIVITIES .......... 4-17

4.8 POST-MAINTENANCE TESTING ........... 4-20

4.9 PROCUREMENT OF PARTS, MATERIALS, AND SERVICES $\ldots \ldots$ 4-22

4.10 MATERIAL RECEIPT, INSPECTION, HANOLING, STORAGE,

RETRIEVAL, AND ISSSUANCE $\because$ 4-24

4.11 CONTROL AND CAL IBRATION OF MEASURING AND TEST EQUTPMENT : 4-27

4.12 MAINTENANCE TOOLS AND EQUIPMENT CONTROL $\ldots \ldots . \ldots . . .4$ 4-29

4.13 FACILITY CONDITION INSPECTYON ........... 4-31

4.14 MANAGEMENT INYOLVEMENT ............... 4-33

4.15 MAINTENANCE HISTORY .............. 4-35

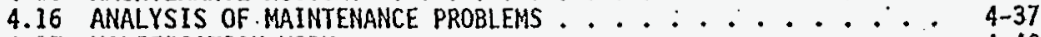

4.17 MODIFICATION WORK $\ldots \ldots . . . . . .4440$

4.18 ADDITIONAL MAINTENANCE MANAGEMENT REQUIREMENTS $\ldots \ldots 4-41$

5.0 DEVIATIONSS REQUESTED HITH SUPPORTING RATIONALE . . . . . . 5-1

6.0 SELF-ASSESSMENT SCHEQULE . .............. 6-1

7.0 REFERENCES .......................... 
HNF-SP-0839, Rev. 02

\section{TERMS}

ALARA

BWHC

CY

DOE

FFTF

FSAR

FY

INPO

IP

LMFBR

M\&TE

MEL

MIP

MOP

NIST

OJT

PIC

PM

SEL

TPAP as low as reasonably achievable B\&W Hanford Company

calendar year

U.S. Department of Energy

Fast Flux Test Facility

final safety analysis report

fiscal year

Institute of Nuclear Power Operations

internal procedure

liquid metal fast breeder reactor

measuring and test equipment

master equipment list

maintenance implementation plan

Management Oversight Program

National Institute of Standards and Technology on-the-job training

person in charge

preventive maintenance

safety equipment 7 ist

training program accreditation plan 
HNF-SP-0839, Rev. 02

This page intentionally left blank: 


\subsection{EXECUTIVE SUMMARY}

This plan implements the U.S. Department of Energy (DOE) 4330.4B, Maintenance Management Program (1994), at the Fast Flux Test Facility (FFTF). The FFTF is a research and test reactor located near Richland, Washington, and is operated under contract for the DOE by the B\&W Hanford Company (BWHC). The intent of this Maintenance Implementation Plan (MIP) is to describe the manner in which the activities of the maintenance function are executed and controlled at the FFTF and how this compares to the requirements of DOE 4330.4B. The MIP is a Tiving document that is updated through a Facility Maintenance Self-Assessment Program. During the continuing self-assessment program, any discrepancies found are resolved to meet DOE $4330.4 \mathrm{~B}$ requirements and existing practices. The philosophy of maintenance management at the FFTF is also describe within this MIP.

This MIP has been developed based on information obtained from various sources including the following:

- A continuing self-assessment against the requirements of the Conduct of Maintenance Order

- In-depth reviews conducted by the members of the task team that assembled this MIP

- Inputs from routine audits and appraisals conducted at the facility

The information from these sources is used to identify those areas in which improvements could be made in the manner in which the facility conducts maintenance activities. The action items identified in Rev. 1 of the MIP have been completed.

The MIP is arranged in six sections. Section 1 is this Executive Summary. Section 2 describes the facility and its history. Section 3 describes the philosophy of the graded approach and how it is applied at FFTF. Section 3 also discusses the strategy and the basis for the prioritizing resources. Section 4 contains the detailed discussion of the elements of DOE 4330.4B and their state of implementation. Section 5 is for waivers and requested deviations from the requirements of the order. Section 6 contains a copy of the Maintenance Self-Assessment Schedule for the FFTF.

In January 1997, the Secretary of Energy declared that DOE-HQ planned to place the FFTF in a hot standby condition. 
HNF-SP-0839, Rev. 02

This page intentionally left blank. 
HNF-SP-0839, Rev. 02

\subsection{BACKGROUND}

The FFTF is a 400-MH, sodium-cooled, Tow-pressure, high-temperature, fast-neutron-flux, nuclear-fission-reactor plant designed and constructed for irradiation testing of breeder reactor fuels and materials. The reactor provides extensive capability for in-core irradiation testing, including eight core positions that may be used with independent instrumentation for the test specimens. In addition to irradiation testing capabilities, the FFTF provides long-term testing and evaluation of plant components and systems for liquid metal fast breeder reactor (LMFBR).

Although the plant was not designed to breed fuel or produce electricity, the FFTF Program has provided valuable information for follow-on LMFBR projects and base technology programs in the areas of plant, system, and component design; component fabrication; prototype testing; and site construction. The FFTF has been utilized as a materials testing location for reactor licensing activities for foreign and domestic utilities, for isotope production research, and in the nuclear fusion research program.

B\&W Hanford Company operates the FFTF for the DOE. The facility is operated 24 hours a day by 5 operating crews on 12-hour rotating shifts. Maintenance activities are conducted by a dedicated force of plant-qualified craftspeople and maintenance supervisors under the direction of the maintenance manager. The FFTF plant manager and the maintenance manager work closely together to ensure that plant operational and maintenance goals are met in an efficient, effective manner.

Plant construction began in July 1970, with initial criticality occurring in August 1979. Full power operation began with the first operating cycle beginning on April 16, 1982; a cycle normally has 50 to 100 effective full power days of operating time and.a sufficient number of days of outage to complete the required reactor refueling and plant maintenance activities. In April 1992 the FFTF was ordered into a standby condition, to be maintained operationally ready until either a long-term mission is found or the decision is made to terminate the project.

Direction was given by the DOE-HQ on December 15, 1993 for Advanced Reactors Transition (ART) to transition the FFTF to a radiologically and industrially safe shutdown condition. The DOE-HQ on November 30, 1995, directed that a hold be placed on the draining of the secondary heat transport system sodium for an indefinite period to allow ample time to evaluate the FFTF for an alternative mission. In January 1997, FFTF was placed in a hot standby condition by DOE-HQ. 
HNF-SP-0839, Rev. 02

This page intentionally left blank. 
HNF-SP-0839, Rev. 02

\subsection{U.S. DEPARTHENT OF ENERGY 4330.4B REQUIRENENTS}

\section{1 maINTENANCE PROgRaN SCOPE}

The maintenance program for the 400 Area, FFTF Plant and plant support facilities includes the reactor plant, reactor support systems and equipment, Maintenance and Storage Facility, plant buildings, building support systems, and the personnel support facilities and buildings.

The FFTF maintenance program conducts the corrective and preventive maintenance necessary to ensure the operational reliability and safety of the reactor plant and support equipment. This comprehensive maintenance program also provides for maximizing the useful life of plant equipment and systems to realize the most efficient possible use of resources.

\subsection{MAINTENANCE PROGRAM REQUIREMENTS}

The FFTF maintenance program has been established based on the requirements of the plant safety analysis report, technical specifications, accepted codes and standards, sound industry practices and experience, and equipment manufacturer recommendations. Maintenance activity and the leve] and depth of the required maintenance and maintenance certification are based on equipment safety classification and the significance of the maintenance activities being performed.

\subsection{SELF-ASSESSMENT PROGRAM}

Assessment activities at the FFTF currently consist of periodic scheduled Management Oversight Program (MOP) tours, assessments and audits from the various internal organizations, the day-to-day monitoring of maintenance that is performed by the maintenance supervision and work control organization, and by external audit and oversight. External audit and oversight includes organizations such as Facility Evaluation Board, DOE, Defense Nuclear Facility Safety Board, etc.

A formal program of periodic self-assessment has been developed and implemented at FFTF to monitor all areas of faciljty operations, including the areas of Conduct of Maintenance and compliance with the letter and intent of DOE 4330.4B (1994). This program includes the approach, philosophy, and technical guidance necessary to ensure that consistent, reproducible, and meaningful data are obtained. Action-item reporting, responsibility assignment, analysis, and tracking will be accommodated by this program. 
HNF-SP-0839, Rev. 02

\subsection{GRADED APPROACH STRATEGY}

\subsection{Overall Strategy and Basis}

At the FFTF a graded approach is used to identify and direct the required resources at an appropriate and effective level of commitment to ensure the safe, reliable, and responsible operation of the facility. The correct application of this strategy to faciljty maintenance activities enhances the ability of the FFTF to meet its schedule and customer obligations with no significant risk to the environment, health, or safety.

The foundation for the application of this graded approach at FFTF was laid down during the construction of the facility in the 1970's. The decision was made by facility management at that time to meet or exceed all of the then current and projected nuclear industry regulatory requirements and "Good Practices." To obtain and then maintain the certification of facility systems, equipment, and procedures a method of assigning "impact-level" classifications was developed and implemented. This system has now evolved such that a safety class is assigned to components and systems as they relate to public safety (SC1/SC2) and industrial safety (SC3). Approval designators are assigned to documents that facilitate the installation, maintenance, repair and modification of all components and systems within the facility. The designated safety class of the equipment and the type of work to be done are considered together to arrive at the approval designators for each document. The approval designator then guides the responsible parties to obtain the appropriate oversight approvals and supporting documentation (such as analyses, certifications, procedures, etc.) required for a particular maintenance activity. The work management process controls these designations, and ensures that adequate reviews are conducted prior to performance of work, that appropriate oversight is maintained during the work, that the retest of the equipment is appropriate to its safety class and the work performed on $i t$, and that a post-work review is performed to verify that the work was performed as specified.

Each component and system was individually identified when installed and a complete master equipment 7 ist (MEL) was compiled. The MEL currently resides as an electronic data base in the software that facilitates our work management process and is under formal administrative change control. Administrative procedures ensure that equipment additions, deletions, and system modifications are incorporated into the MEL in a timely fashion. The MEL is a cornerstone of the FFTF work control system and allows for accurate tracking of equipment and system status and condition.

A subset of the MEL is our safety equipment Tist (SEL). Items in the SEL have been assigned a safety class in a manner equivalent to the safety classifications used by the commercial nuclear industry and provides FFTF with the ability to cross reference system maintenance activities with their functional equivalents throughout the industry.

Since inception the facility has been operated in a manner consistent with the philosophy of Conduct of Maintenance and Conduct of Operations. The concept of the graded approach is integral to the operational philosophy and to the manner in which facility operations are conducted. 


\subsubsection{Strategy for Safety Related Items}

The work control process currently in use ensures that appropriate actions are taken. These actions include the assignment of levels of review and approval, procedural detail requirements, documentation, oversight, and verification. Priorities are assigned based on the importance of the work to safety, quality, and reliability. The assignment of work priorities and the allocation of resources to plant work is made on the basis of safety class with deficiency correction taking priority over enhancement.

The construction of the SEL was completed in the fourth quarter of Fiscal Year (FY) 1992. This completed the assignment of safety classifications for FFTF components and systems in accordance with Site safety classification criteria. These classifications are used throughout the work control program.

Since the FFTF is in transition to shutdown, the SEL has not been revised to acknowledge the latest revision of WHC-CM-4-46. The present approach will be to address the safety classification of equipment when required by modification documents or other reports. New facilities at FFTF will include the new nomenclature, safety function, and performance category. If the FFTF receives a restart order from DOE, the FFTF will fully implement the latest revision to WHC-CM-4-46. This will include updating the SEL to the new safety class nomenclature.

Following is a brief summary of the Safety $\mathrm{Classes}$ and the level of supervisory control, procedural oversight, performance skills and training required in support of the activities associated with the classes.

- Safety Class 1--Systems, components, and structures, including portions of process systems, whose failure could result in a threat to the environment, or the health and safety of the public. Activities will require the highest level of work instruction detail, craft skills, and supervision.

- Safety Class 2--Systems, components, and structures, including portions of process systems not defined as Safety Class 1, that could result in a threat to onsite worker health and safety and the environment. Activities wil1 require a moderate level of work instruction detail, craft skills, and supervision.

- Safety Class 3--.Systems, components, and structures, including portions of process systems not defined as Safety Class 1 or 2, that could resuit in a threat to the health and safety of facility workers and radioactive, chemical, or thermal releases to the environment. Activities will require a normal level of work instruction detail; craft skills, and supervision commensurate with the complexity of the work activity.

- Safety Class 4--Systems, components, and structures whose failure has no significant importance to safety, health, or environmental protection. Activities will require a minimal level of work instruction detail, craft skills, and supervision. 
HNF-SP-0839, Rev. 02

This page intentionally left blank. 
HNF-SP-0839, Rev. 02

\subsection{U.S. DEPARTMENT OF ENERGY 4330.4B CHAPTER II REQUIREMENTS}

\subsection{MAINTENANCE ORGANIZATION AND ADMINISTRATION}

The organization and administration of the maintenance function should ensure that a high level of performance in maintenance is achieved through effective implementation and control of maintenance activities.

Maintenance Organization Policies

Objective: $\quad$ Site and facility policies are clearly defined and relayed to maintenance personne]. (DOE 4330.4B CHAPTER II SEC.2.3.1 Maintenance Policies)

Discussion: All contractor and plant policies and procedures are incorporated into maintenance administrative procedures and promulgated to the maintenance personnel via-formal and informal training. These procedures define maintenance responsibilities, authority, accountability, and interfaces with other groups. The term maintenance manager is used throughout DOE $4330.4 \mathrm{~B}$ and this MIP to denote the manager responsible and hence accountable for the specific maintenance function discussed.

Improvement: Existing maintenance program practices satisfy the intent of the stated objective.

\section{Maintenance Strategy}

A. Horking Relationships

Objective: Facilities chart relationship among supporting groups, by defining responsibility, authority and accountability. (DOE. 4330.4B CHAPTER II SEC.2.3.2a Working Relationships)

Discussion: Administrative procedures clearly define organizational relationships, authority, accountability, and responsibilities. The maintenance function is supported by operations, engineering, health physics, material management and control, quality assurance $(Q A)$ and control, and work control. Personnel interfaces are defined, formal self-assessments are performed yearly by the quality and safety organizations, and procedural interfaces are well known and expounded. In addition, maintenance indicators related to overall maintenance performance and support of maintenance tracked by each supporting group are tracked and reported to all maintenancefunction stakeholders.

Improvement: Existing maintenance program practices satisfy the intent of the stated objective. 
B. Long-Range P7anning

Objective: Perform long-range planning, by establishing a scope of longrange major activities. (DOE $4330.4 \mathrm{~B}$ CHAPTER II SEC.2.3.2b Long-Range Planning)

Discussion: Long-range planning is the cornerstone of the planning and scheduling process. Plant administrative procedures implement a formal, integrated planning team approach to long-range planning. This team is composed of members from the plant staff and includes maintenance. Planning team members meet weekly to discuss preparations for major projects and modifications, and ongoing work. From this information, the plant management is able to budget and adjust staff as necessary to meet plant goals and commitments.

Improvement: Existing maintenance program practices satisfy the intent of the stated objective.

\section{Staffing Resources}

Objective: Resources are allocated and established to accomplish assigned tasks. (DOE 4330.4B CHAPTER II SEC.2.3.3 Staffing Resources)

Discussion: The maintenance manager is directly involved with the selection of high-quality personnel to fill needed maintenance positions. Position qualifications are established by prescribed position requirements, credentials of candidates are screened, and final selections are made by the hiring maintenance manager. The maintenance staff size is determined by approved budget levers, but is sufficient. Adequate time for personnel training is factored into schedules as part of the planning and scheduling process.

Improvement: Existing maintenance program practices satisfy the intent of the stated objective.

Goals and Objectives

Objective: Facility specific maintenance goals are used to improve performance. (DOE 4330.4B CHAPTER II SEC.2.3.4 Goals and objectives)

Discussion: Maintenance indicators and goals have been developed as a communications tool to more constructively involve cognizant groups in improving maintenance performance, and to help measure maintenance effectiveness. These maintenance indicators, measures and expectations related to current facility objectives and milestones. These indicators are communicated to the staff in a variety of ways (e.g., communication boards, performance charts, employee meetings). 
HNF-SP-0839, Rev. 02

Improvement: Existing maintenance program practices satisfy the intent of the stated objective.

\section{Accountability}

Objective: Performance appraisals and specific discipline policy assure accountability for maintenance performance. (DOE $4330.4 \mathrm{~B}$ CHAPTER II SEC.2.3.5 Accountabijity)

Discussion: A variety of recognition programs are routinely practiced to acknowledge individuals for their performance. Also, a performance appraisal process augmented by routine discussion and feedback is in place.

Improvement: Existing maintenance program practices satisfy the intent of the stated objective. 
HNF-SP-0839, Rev. 02

\subsection{TRAINING AND QUALIFICATION OF MAINTENANCE PERSONNEL}

A maintenance training and qualification program consistent with DOE 5480.18B (1991) and 5480.20A (1994) should be implemented to develop and maintain the knowledge and skills needed by maintenance personnel to effectively perform maintenance activities.

Responsibilities

Objective: Training organization and administration ensures effective implementation and control of training activities. (DOE 4330.4B CHAPTER II SEC.3.3.1 Responsibilities)

Discussion: The responsibilities of the facility and maintenance department training organizations for the establishment and development of training programs are assigned and documented in company and facility policy manuals. This training is reviewed by management and supervision for applicability and technical content (e.g., lesson plans reviewed, class observation or participation).

Improvement: Existing maintenance program practices satisfy the intent of the stated objective.

\section{Naintenance Training Programs}

Objective: Maintenance personnel training qualification programs are developed to improve the knowledge and skills necessary to perform assigned job functions. (DOE 4330.4B CHAPTER II SEC.3.3.2 Maintenance Training)

Discussion: Programs are in $p$ lace to identify training requirements and assure qualification of maintenance personnel. A formal program is in place that establishes mandatory training for all maintenance managers.

Improvement: Existing maintenance program practices comply with DOE $5480.20 \mathrm{~A}$ and DOE 4330.4B.

\section{Training Schedules and Support}

Objective: Schedules are established and implemented for initial and continuing training. (DOE 4330.4B CHAPTER II SEC.3.3.3 Training Schedules and Supports)

Discussion: The training that an employee requires is tracked by a training records management system. The periodic, recurrent, and new7y identified training requirements are scheduled and tracked. This scheduling takes place through the responsible training organization to ensure that appropriate instructors and facilities are available. 
HNF-SP-0839, Rev. 02

Improvement: Existing maintenance program practices satisfy the intent of the stated objective.

\section{on-the-Job Training}

Objective: On-the-job (OJT) training requirements are identified, completed, and documented prior to assignment to perform the task independently. (DOE 4330.4B CHAPTER II SEC. 3.3.4 On-theJob Training)

Discussion: The OJT requirements for maintenance activities on safetyrelated systems are well defined. A graded approach is used to define $0 \mathrm{JT}$ requirements on non-safety related areas of maintenance.

Improvement: Existing maintenance program practices comply with DOE 5480.20A and DOE $4330.4 B$.

\section{Qual ification}

Objective: Training and retraining schedules are maintained to keep a11 personne? adequately qualjfied and/or certified. (DOE 4330.4B CHAPTER II SEC.3.3.5 Qualification)

Discussion: The maintenance supervisors ensure that individuals have completed the required training and qualification before making job assignments. .

Improvement: Existing maintenance program practices satisfy the intent of the stated objective.

Training in Root Cause Analysis

Objective: Technical maintenarice select group or team are schooled in principles and methods of root-cause analysis. (DOE 4330.4B CHAPTER II SEC.3.3.6 Training in Root-Cause Analysis)

Discussion: A staff of individuals trained and experienced in root cause analysis and accident investigation techniques is maintained.

Improvement: Existing maintenance program practices satisfy the intent of the stated objective.

Training Program Approva1, Effectiveness, and Feedback

Objective: Performance indicators are established and used to improve training performance. (DOE 4330.4B CHAPTER II SEC.3.3.7 Training Program Approval, Effectiveness, and Feedback)

Discussion: The maintenance managers and supervisors continually monitor the effectiveness and vaiue of training being given to the 
HNF-SP-0839, Rev. 02

craftspeople by attending training sessions, polling the

individuals as they return from training, and by observing the performance of personnel following training. This information is then fed back to the training organizations.

Improvement: Existing maintenance program practices satisfy the intent of the stated objective.

Management and Supervisory Training

Objective: Training programs to prepare supervisors, managers and technical personnel for assigned responsibilities. (DOE 4330.4B CHAPTER

II SEC.3.3.8 Management and Supervisory Training)

Discussion: A list of required training for maintenance managers has been established. Individual professional skill development plans are discussed between the individual and their immediate manager as part of the annual appraisal review process.

Improvement: Existing maintenance program practices comply with DOE $5480.20 \mathrm{~A}$ and DOE $4330.4 B$. 
HNF-SP-0839, Rev, 02

\subsection{MAINTENANCE FACILITIES, EQUIPMENT, AND TOOLS}

Maintenance facilities, equipment, and tools should efficiently support facility maintenance and maintenance training.

Facilities

Objective: Maintenance facility size, location, and arrangements promote the safe and effective completion of work. (DOE 4330.4B CHAPTER II SEC.4.3.1 Facilities)

Discussion: Each craft has shop areas designed to meet the requirements and needs of that craft. Adequate laydown, staging, and storage areas are provided for equipment, special tools, rigs, and parts. Suitable facilities are available to decontaminate tools and equipment.

Improvement: Existing maintenance program practices satisfy the intent of the stated objective.

\section{Tool and Equipment Storage}

Objective: Storage facilities for tools, test equipment, and consumable supplies are available. (DOE 4330.4B CHAPTER II SEC.4.3.2 Tools and Equipment Storage)

Discussion: Each shop discipline has adequate storage in its shop areas for hand tools required for everyday tasks. The tool crib is also used to store and control hand tools and maintenance equipment. The tool crib is also used to control and segregate maintenance and test equipment.

Improvement: Existing maintenance program practices satisfy the intent of the stated objective.

\section{Office Equipment}

Objective: Maintenance facilities includes office equipment that supports the maintenance organization in a high quality manner. (DOE 4330.4B CHAPTER II SEC.4.3.3 Office Equipment)

Discussion: Office equipment is available to support maintenance efficientiy. Communication equipment and other office equipment is readily available and maintained in reliable working condition. Maintenance personnel have access to the Hanford Site computerized local area network.

Improvement: Existing maintenance program practices satisfy the intent of the stated objective. 
HNF-SP-0839, Rev. 02

\subsection{TYPES OF MAINTENANCE}

A proper balance of corrective and preventive maintenance should be employed to provide a high degree of confidence that facility equipment degradation is identified and corrected, that equipment life is optimized, and that the maintenance program is cost effective.

\section{Master Equipment List}

Objective: Master Equipment List of both safety-reiated and non-safetyrelated equipment exist, and are used. (DOE 4330.4B CHAPTER II SEC.5.3.1 Master Equipment List)

Discussion: A comprehensive equipment and component master list currently exists and is part of a plant computer database. This list was used to develop the existing preventive-maintenance database. This system is used to increase the efficiency, safety, and control of work processed for release. It is the principal tool used for planning and scheduling plant work. These databases, and changes to them, are controlled and maintained in accordance with administrative procedures.

Improvement: Existing maintenance program practices satisfy the intent of the stated objective.

\section{Types of Maintenance}

\section{A. Corrective Maintenance}

Objective: A corrective maintenance (CM) program is in existence. (DOE 4330.4B CHAPTER II SEC.5.3.2a Corrective Maintenance)

Discussion: A we11-documented $C M$ program founded on a graded approach to safety and quality control has been established. Corrective maintenance activities may be identified in several ways: by failure of equipment or components; during performance of facility final safety analysis report (FSAR) compliance and surveillance procedures; during performance of operations equipment condition inspections; or by direct observations of employees. Administrative procedures incorporate a detailed process for work performance in the facility. This process describes and controls the flow of CM from discovery of a maintenance activity through final document archiving.

Improvement: Existing maintenance program practices satisfy the intent of the stated objective. 
HNF-SP-0839, Rev, 02

\section{B. Preventive Maintenance}

Objective: A preventive maintenance (PM) program is in existence.

(DOE 4330.4B CHAPTER II SEC.5.3.2b Preventive Maintenance)

Discussion: A PM program is established by administrative procedures. This program is centered around manufacturer's recommendations, and program requirements are periodically updated based on plant experience and sound engineering judgement. Preventive maintenance scheduling and tracking is coordinated using a computerized database that provides standard scheduling and historical information concerning performance of all preventive and predictive maintenance and instrument calibration recall. A11 PM and instrument calibrations performed to verify compliance with the plant FSAR are completed within the allowed frequencies.

Improvement: Existing maintenance program practices satisfy the intent of the stated objective.

c. Predictive Maintenance

Objective: A predictive maintenance program is in existence. (DOE 4330.4B CHAPTER II SEC.5.3.2c Predictive Maintenance)

Discussion: The predictive maintenance program is defined by administrative procedures. Elements of this program can include vibration analysis of a11 major plant motors and rotating equipment, oil sample analysis of all major prime movers, onsite infrared spectroscopy analysis capabitities, and engineering review of nonroutine preventive maintenance activities. Maintenance history records are maintained on computer databases and actual work packages are maintained for the life of the plant.

Improvement: Existing maintenance program practices satisfy the intent of the stated objective.

Maintenance Action and Frequency Selection

Objective: The effectiveness of the PM program is periodically evaluated to improve equipment performance. (DOE $4330.4 \mathrm{~B}$ CHAPTER II SEC.5.3.3 Maintenance Action and Frequency Selection)

Discussion: The PM program is a living program controlled and changed in accordance with administrative procedures. The PM actions are based on the FFTF Plant FSAR, regulatory and code requirements, and vendor recommendations. In addition, the PM program is changed based on experience at FFTF and other facilities. These program changes are based on sound engineering judgement, costto-benefit evaluations and maintenance history trend studies. System cognizant engineers formally review PM program requirements during their system assessment reports. 
HNF-SP-0839, Rev. 02

Improvement: Existing maintenance program practices satisfy the intent of the stated objective.

\section{Scheduling}

Objective: Scheduling, and control of identified maintenance actions are properly completed in a safe, timely, and effective manner. (DOE 4330.4B CHAPTER II SEC.5.3.4. Scheduling)

Discussion: Procedures are in place that describe the scheduling priority system and ensure that the right activity is released for work at the proper time. The planning and scheduling organizations ensure that related activities are coordinated to minimize equipment outages.

Improvement: Existing maintenance program practices satisfy the intent of the stated objective. 
HNF-SP-0839, Rev. 02

\subsection{MAINTENANCE PROCEDURES}

Maintenance procedures and other work-related documents, such as drawings and instructions, should be prepared and used to provide appropriate work direction and to ensure that maintenance is performed safely and efficiently.

\section{Procedures Development and Writing}

Objective: Maintenance procedures are prepared by well-qualified personnel, knowledgeable about -maintenance standards and administrative procedures, and familiar with the system and equipment involved. (DOE 4330.4B CHAPTER II SEC.6.3.1 Procedure Development and Writing)

Discussion: Administrative procedures contain the requirements and guidelines for preparing $p$ lant maintenance procedures. Maintenance procedures are written by cognizant plant personnel including engineering, maintenance, and operations personnel. A11 maintenance procedures are reviewed for their impact on safety and quality. As a minimum, maintenance procedures are reviewed and approved by the cognizant engineer and his manager. Maintenance procedures have a consistent format and include sections that incorporate appropriate signatures, impact to safety and quality, task description, references, precautions and limitations, materials required to perform the procedure, retest of equipment/component after return to service to ensure full operability, and a signoff section where craftsperson, operator, quality control representative, safety representative, or others certify performance of steps.

Improvement: Existing maintenance program practices satisfy the intent of the stated objective.

Procedure Verification

- Objective: The review and revision of procedures and documents are properiy controlled. (DOE 4330:4B CHAPTER II SEC.6.3.2 Procedure Verification)

Discussion: New and revised maintenance procedures are reviewed and approved by appropriate personnel. This review ensures that the technical content of the procedures is adequate to successfully accomplish the stated task. Maintenance procedures that affect quality control, reactor or facility safety, or radiological controls are reviewed and approved by the respective oversight organizations, where appropriate.

Improvement: Existing maintenance program practices satisfy the intent of the stated objective. 
Procedure Validation

Objective: Procedures are validated prior to use. (DOE 4330.4B CHAPTER II SEC.6.3.3 Procedure Val idation)

Discussion: New and revised maintenance procedures are validated as required by administrative procedures. The validation techniques used include validation by walk-through, by reference (i.e. the change to the procedure or the new procedure has previous7y been performed), by table-top discussion, by mock-up of the maintenance, or by actually performing the maintenance procedure for the first time.

Improvement: Existing maintenance program practices satisfy the intent of the stated objective.

Procedure Approva1

Objective: The approval of procedures are properly controlled. (DOE 4330.4B CHAPTER II SEC.6.3.4 Procedure Approval)

Discussion: Maintenance procedures are approved by appropriate personne]. As a minimum, the maintenance manager or designate.

Improvement: Existing maintenance program practices satisfy the intent of the stated objective.

Procedure Use

Objective: Procedures are clear, concise, and contain adequate information for users to understand and perform their activities safely and effectively. (DOE 4330.4B CHAPTER II SEC.6.3.5 Procedures Use)

Discussion: Maintenance procedures are issued from controlled files. These controlled procedures are reviewed by cognizant facility. personnel before the work is released to the field to ensure that only up-to-date and currently valid procedures are available for task performance. Procedures are followed in accordance with current administrative requirements.

Maintenance and operations personnel are trained to stop work and notify their supervisors if procedures cannot be followed as written or unexpected results occur.

Improvement: Existing maintenance program practices satisfy the intent of the stated objective.

Procedure Control, Periodic Review, and Revision

Objective: A policy governing the use of procedural control, revision, and periodic review is implemented. (DOE 4330.4B CHAPTER II SEC.6.3.6 Procedure Control, Periodic Review, and Revision) 


$$
\text { HNF-SP-0839, Rev. } 02
$$

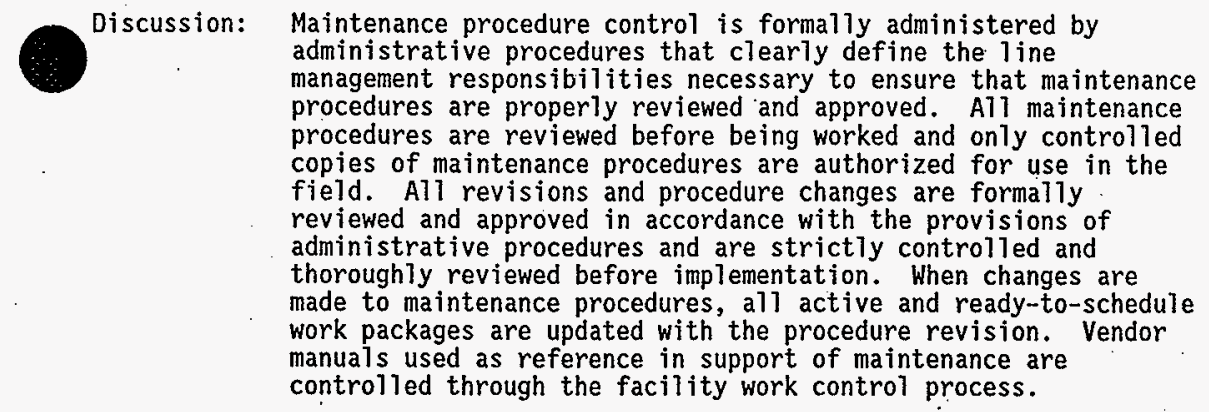

Improvement: Existing maintenance program practices satisfy the intent of the stated objective. 


\subsection{PLANNING, SCHEDULING, AND COORDINATION OF MAINTENANCE}

An effective system for planning, scheduling, and coordinating maintenance activities should be implemented to: ensure that maintenance is accomplished in a timely manner; improve maintenance efficiency; reduce radiation exposure to as-low-as-reasonably-achievable (ALARA) levels; and increase equipment availability.

\section{Planning for Maintenance Activities}

\section{A. Planning Group Organization}

Objective: Maintenance planning is performed by a group that is dedicated to this function. (DOE 4330.4B CHAPTER II SEC.7.3.1a Planning Group Organization)

Discussion: Maintenance planning is performed by a centralized, dedicated group. This group plans and coordinates all facility work in accordance with administrative procedures.

Improvement: Existing maintenance program practices satisfy the intent of the stated objective.

\section{B. Planning Group Responsibitities}

Objective: All work packages are previewed and post reviewed by $\mathrm{planning.}$ (DOE 4330.4B CHAPTER II SEC.7.3.1b Planning Group Responsibilities)

Discussion: Maintenance planning reviews all work documents generated in the facility before package disposition and release to work in the field to verify the validity of the work request. A planner then reviews the package before facility release to ensure the correct resources are assigned, estimate resource hours, and provide additional documentation, such as instrument calibration data cards, radiation work permits, and drawings. The planner also reaches an understanding of the special requirements of the job; such as staging of special material or equipment and use of outside vendors. The maintenance planning group reviews every work package after the work has been completed to verify that the package is complete. The package is then closed out and the history record sent to archive for long-term storage and retrieval. Al] original work documents are maintained for the life of the facility.

Improvement: Existing maintenance program practices satisfy the intent of the stated objective. 
HNF-SP-0839, Rev. 02

\section{Scheduling of Maintenance Activities}

A. Control of Maintenance Backlog

Objective: The maintenance backlog is controlled and effectively managed. (DOE 4330.4B CHAPTER II SEC.7.3.2a Control of Maintenance Back log)

Discussion: A computer database tracks corrective and non-corrective maintenance and action-item due dates to ensure that these activities are completed on schedule. The PM database tracks preventive-maintenance-activity due dates and retains a history of preventive-maintenance performance. These systems are used to build a weekly schedule from which a plan-of-the-day is generated daily. Every attempt is made to complete corrective and preventive maintenance activities in a timely manner. The planned corrective and preventive maintenance activities are tracked and status is reported weekly to line management. FSAR and selected other maintenance items related to safety are not allowed to go past due. Management approves the preventive maintenance overdue $l i$ ist before the start of each work phase.

Improvement: Existing maintenance program practices satisfy the intent of the stated objective.

B. Work Priority

Objective: Management control of work is accomplished through the use of an effective priority assignment system. (DOE 4330.4B CHAPTER II SEC.7.3.2b Work Priority)

Discussion: Each work request is processed initially through Operations management for a review for impact on plant and personnel safety and plant operating reliability. The operations, engineering, maintenance and work-control groups interface closely to establish the proper priority of work based on a graded approach to facility and personnel safety, quality control, and environmental impact. Work is divided not only by priority, but by whether the work is corrective or non-corrective maintenance, technical specification surveillance, plant modification, instrument calibration, or preventive maintenance. This separation of work by priority and type of work ensures that the necessary work is performed to enhance facility. safety, improve total quality, minimize environmental impact, and elevate plant availability and reliability.

Improvement: Existing maintenance program practices satisfy the intent of the stated objective. 
HNF-SP-0839, Rev. 02

Coordination of Majntenance Activities

Objective: Coordination of maintenance activities with support organization is complete through periodic and frequent meetings. (DOE. 4330.4B CHAPTER II SEC.7.3.3 Coordination of Maintenance Activities)

Discussion: The status of all open work requests is maintained on a computer database and is used by scheduling staff to coordinate daily activities. A preliminary planning meeting is held once each week where work is coordinated with operations, quality control, engineering, surveillance scheduling, and work-control

electrical and mechanical scheduling. The weekly plant schedule is a product of this meeting and is an integrated schedule that defines what work will be accomplished the next work week. Each day a plan-of-the-day schedule is issued to track this weekly planning effort. A daily plan-of-the-day meeting is held with maintenance supervision, scheduling, operations, and other workcontrol personnel to status the ongoing work, to jdentify problem areas, and to discuss emergent work. A briefing is held at the end of each day to inform management of activities that occurred that day and to discuss backshift work plans. Schedules are developed with packages that are ready to schedule. These packages have been reviewed by maintenance supervision and problem areas are identified before packages are. released for field work.

Improvement: Existing maintenance program practices satisfy the intent of the stated objective.

Outage Planning, Scheduling, and Coordination

Planned Outages/Forced Outages

Objective: Advanced planning is established for scheduled and unscheduled outages. (DOE 4330.4B CHAPTER II SEC.7.3.4 Outage Planning, Scheduling, and Coordination)

Discussion: Due to plant condition, advanced planning of planned and forced outages is not applicable.

Improvement: Existing maintenance program practices satisfy the intent of the stated objective. 


\subsection{CONTROL OF MAINTENANCE ACTIVITIES}

Management-directed and-delegated involvement in control of maintenance activities should ensure that maintenance practices are effective in maintaining safe and reliable facility operation.

\section{Work Control Procedure}

Objective: Policies are established for overall direction of the Hork Control System. (DOE 4330.4B CHAPTER II SEC.8.3.1 Work Control Procedure)

Discussion: The work control system is controlled by administrative procedures that fully define the work control process for routine maintenance, plant modification, PM, surveillance, and in-service testing. In addition, the corrective action management program uses the work control forms and process to effectively manage corrective action tracking and completion. These administrative procedures define standard forms and attachments and address responsibilities associated with identification and documentation of deficiencies. They control the conduct of maintenance, work request processing from identification of deficiency to post-performance review, work priority system, determination of work impact, work planning and scheduling, conduct of planning and scheduling meetings, requirements for personnel and equipment safety and radiological protection, and collection of maintenance history.

Improvement: Existing maintenance program practices satisfy the intent of the stated objective. .

Work Request

Objective: Proper work request packages are prepared for all work. (DOE 4330.4B CHAPTER II SEC.8.3.2 Hork Request)

Discussion: Work requests contain all the requirements listed in the objectives outlined in DOE $4330.4 \mathrm{~B}$ to ensure work is properly performed.

Improvement: Existing maintenance program practices satisfy the intent of the stated objective.

\section{Supervision of Maintenance Activities}

objective: Maintenance managers and supervisors take an active role in maintenance activities being performed, prejob briefings, quality of workmanship, work progress and procedure use. (DOE 4330.4B CHAPTER II SEC.8.3.3 Supervision of Maintenance Activities) 


$$
\text { HNF-SP-0839, Rev. } 02
$$

Discussion: Work is routinely monitored by the person-in-charge (PIC) and maintenance supervisors who have been specifically trained to address proper adherence to facility administrative requirements and to ensure work is completed properly and efficiently. Maintenance supervision routinely performs prejob briefings, monitors work in the field, and reviews work packages before package submittal for post-maintenance testing. Plant management also conducts MOP tours frequently to ensure that maintenance activities are conducted in accordance with DOE and facility policies and procedures. The MOP tour reports are routed to management for action item review and closeout. Recognition is regularly used to commend good maintenance practices, while poor maintenance practices are identified and corrected when noted. Post job critiques are used when applicable.

Improvement: Existing maintenance program practices satisfy the intent of the stated objective.

\section{Review of Completed Hork Requests}

Objective: Post-maintenance test results are documented and reviewed to ensure proper system/equipment performance prior to returning the system to service. (DOE 4330.4B CHAPTER II SEC.8.3.4 Review of Completed Work Requests)

Discussion: All work packages and surveillance procedures are reviewed by a qualified Operations Engineer for conformance to administrative guidelines, completeness of work, and post-maintenance test requirements. The maintenance supervisor also reviews the completed work package for completeness and adequacy of repair before the package is submitted to operations for retest and closeout. The package is then forwarded to Work Control where it is reviewed for adequacy and thoroughness before closeout. All packages related to safety or quality assurance are reviewed by the appropriate safety or quality assurance group before closeout. These requirements are outlined in appropriate facility administrative procedures. Post-job reviews are conducted through the work management process utilizing a graded approach.

Improvement: Existing maintenance program practices satisfy the intent of the stated objective.

Temporary Repairs

Objective: Procedures are in $\dot{\mathrm{p}}$ lace to assure permanent corrective action is taken, whenever temporary repairs have been made to allow equipment/systems to remain in service. (DOE.4330.4B CHAPTER II SEC.8.3.5 Temporary Repairs)

Discussion: Temporary repair/modification work is conducted in the same manner and is controlled by the same administrative procedures 
HNF-SP-0839, Rev. 02

that control maintenance activities. Temporary modifications are suspended after implementation and returned to Hork Control for tracking purposes. The temporary modification will be made permanent or the plant will be restored within a specified time.

Improvement: Existing maintenance program practices satisfy the intent of the stated objective.

Control of Non-facility Contractor and Subcontractor Personnel

Objective: Non-facility contractor and subcontractor personnel who perform maintenance activities at the facility meet the same requirements expected of facility maintenance as to training and high quality work standards. (DOE 4330.4B CHAPTER II SEC.8.3.6 Control of Non-facility Contractor and Subcontractor Personnel)

Discussion: All unescorted access to FFTF requires training that covers the basic safety, radiological protection requirements, and facility-specific requirements to ensure safe work practices. Construction projects and vendor-oriented or -supported work comply with the requirements contained in administrative procedures. The work to be performed is identified on the facility work request form and processed in accordance with facility administrative guidelines. In addition, an FFTFqual ified PIC will be assigned to the work to ensure adherence to policies, procedures, and practices.

Improvement: Existing maintenance program practices satisfy the intent of the stated objective. 
HNF-SP-0839, Rev. 02

\subsection{POST-MAINTENANCE TESTING}

Post maintenance testing should be performed to verify that components will fulfill their design function when returned to service after maintenance.

Post-Maintenance Test Requirements

Objective: A program that is part of the work control system is established to control and document post-maintenance testing. (DOE 4330.4B CHAPTER II SEC.9.3.1 Post-Maintenance Test Requirements)

Discussion: Post-maintenance testing (retest) is an integral part of the FFTF work control process and is controlled by administrative procedures. Each maintenance action requires that appropriate retest actions be defined as part of the individual work request. Where standard tests apply, they are so indicated in the retest section of the work request.

Improvement: Existing maintenance program practices satisfy the intent of the stated objective.

Post-Maintenance Test Program Scope

Objective: Program scope includes types of equipment to be tested and type of test to be performed. (DOE 4330.4B CHAPTER II SEC.9.3.2 Post-Maintenance Test Program Scope)

Discussion: Post-maintenance testing is an integral part of the FFTF work control process. It is strictly controlled and thoroughly documented in plant administrative procedures.: Disposition of the work request requires that critical system relationships be defined. Work that affects safety systems, technical specifications, American Society of Mechanical Engineers codes, etc., require rigorous retesting to verify their acceptability for operation.

Improvement: Existing maintenance program practices satisfy the intent of the stated objective.

Post-Maintenance Test Control

Objective: The program designates organizations responsible for test control. (DOE 4330.4B CHAPTER II SEC.9.3.3 Post-Maintenance Test Control)

Discussion: Post-maintenance testing is an integral part of the FFTF work control process. It is strictly controlled and thoroughly documented in piant administrative procedures. Administrative procedures require all retests to be completed before a work package can be closed. The status of all open packages is tracked, reviewed, and reported on a frequent basis. 
HNF-SP-0839, Rev. 02

Improvement: Existing maintenance program practices satisfy the intent of the stated objective.

Post-Maintenance Test Performance, Documentation, and Acceptance

Objective: The program controls Test Performance, Documentation, and Acceptance. (DOE 4330.4B CHAPTER II SEC.9.3.4 Post-Maintenance Test-Performance, Documentation, and Acceptance)

Discussion: Post-maintenance testing is an integral part of the FFTF work control process. It is strictly controlled and thoroughly documented in plant administrative procedures. All retests are documented in the work package, and Operations certifies when the retest is completed. Work package close-out progresses through a normal chain of events, which includes post reviews by work control, engineering, quality assurance, and safety as appropriate.

Improvement: Existing maintenance program practices satisfy the intent of the stated objective. 
HNF-SP-0839, Rev. 02

\subsection{PROCUREMENT OF PARTS, MATERIALS, AND SERVICES}

Parts, materials, and services required for maintenance activities should be available when needed.

\section{Procurement Policy and Procedures}

Objective: Policies are established for the procurement of parts, material, and services. (DOE 4330.4B CHAPTER II SEC.10.3.1 Procurement Policy and Procedures)

Discussion: Procedures have been established for the procurement of all parts, materials, and services. These procedures define in detail all responsibilities for those individuals and organizations involved in procurement activities. A11 design changes are reviewed for their effect on spares. This review considers the need for new spares and the effect on existing spares.

Improvement: Existing maintenance program practices satisfy the intent of the stated objective.

\section{Procurement Initiation}

Objective: Timety procurement of services, and adjustments to parts, and material stock levels necessary to meet plant needs. (DOE 4330.4B CHAPTER II SEC.10.3.2 Procurement Initiation)

Discusșion: Spare parts, spare equipment, and special tools are established in inventory as appropriate to maintain continuity of facility operations and reduce system and facility downtime through availability of equipment, parts, and components. Spare parts are identified through common inventory reviews and original equipment manufacturers' recommended spare parts lists. Stock levels are established based on prior maintenance and equipment history, procurement lead-time factors and shelf-life considerations. A system is used to track vendor performance and is used to evaluate vendors' performance.

Improvement: Existing maintenance program practices satisfy the intent of the stated objective.

\section{Procurement Control}

Objective: Material is inspected to ensure conformance to purchasing requirements. (DOE 4330.4B CHAPTER II SEC.10.3.3 Procurement Control)

Discussion: Procedures are in place that provide specific instructions when routing incoming shipments of general supplies, spare parts, and direct-charge items for receiving inspection. These procedures identify, control, and prevent nonconforming items from entering 
HNF-SP-0839, Rev. 02

the inventory control system before final acceptance. Al1 designated material is receipt inspected in accordance with purchase order requirements.

Complete receiving inspection documentation packages are classified as lifetime quality assurance records. Lifetime records are required to be maintained for the life of the particular item while it is installed in the plant or stored for future use.

Improvement: Existing maintenance program practices satisfy the intent of the stated objective.

\section{Services}

Objective: Procedures are in place to assure timely response from vendors for required specialized services. (DOE 4330.4B CHAPTER II SEC.10.3.4 Services)

Discussion: Sufficient guidance and procedural direction has been provided for the procurement of services. These procedures define the warranted and unwarranted conditions for use of service contracts. In addition, provisions are provided for expeditious procurement of services in cases of emergency need to preclude impact on the facility.

Improvement: Existing maintenance program practices satisfy the intent of the stated objective. 
HNF-SP-0839, Rev. 02

4.10 MATERIAL RECEIPT, INSPECTION, HANDLING, STORAGE, RETRIEVAL, AND ISSUANCE

Al1 phases of receiving, inspecting, handling, storing, retrieving, and issuing equipment, parts, and material for maintenance of the FFTF will be defined by effectively implemented policies and procedures.

\section{Receipt and Inspection}

Objective: Organizational responsibilities are described for the inspection of purchased material, equipment, including interfaces between design, procurement, and QA organizations. (DOE 4330.4B CHAPTER II SEC.11.3.1 Receipt and Inspection)

Discussion: Procedures and policies are in place to require and define the receipt of material. This receipt verifies the correct item received, inspection to acceptance requirements and documentation of items received, and maintenance of files. Standard engineering practice documents specify the responsibilities for technical staff in addressing procurement issues. Receiving and inspection areas have been established and the following controls have been implemented:

1. Controlled access to the receiving/inspection areas allowing only authorized personne] entrance.

2. Quality Assurance hold area established for nonconforming items and instructions to personnel that does not allow release of items requiring Quality control inspection until the nonconformance has been dispositioned.

3. A designated hold area with identifying signs and posters.

4. A hold tag attached to the nonconforming item and placement in the designated area.

Procedures contain provisions for the control of items with limited shelf life. Materials Management inventories items with limited shelf life and controls, reviews, and purges as necessary to ensure that this inventory is current and fresh.

Improvement: Existing maintenance program practices satisfy the intent of the stated objective.

Handling

Objective: Documentation is prepared for handling requirements of special equipment, including manufacturers certification and instructions. (DOE 4330.4B CHAPTER II SEC.11.3.2 Handling)

Discussion: Approved procedures, instructions, specifications, and shipping instructions are established for the control of handling, storing, cleaning, packaging, preserving, and shipping items to 


$$
\text { HNF-SP-0839, Rev. } 02
$$

prevent damage or Toss and to minimize deterioration. Itemspecific procedures are used for critical, sensitive, perishable, or high-value articles. Special-handling tools and equipment that are inspected and tested in accordance with established procedures are used to ensure safe moving, handling, and lifting of store items. Operators of special handling and lifting equipment are experienced, trained, and qualified.

Improvement: Existing maintenance program practices satisfy the intent of the stated objective.

\section{Storage Material and Equipment}

Objective: A program is in place that provides periodic inspections of storage material, and equipment which complies with requirements supplied by the vendor. (DOE 4330.4B CHAPTER II SEC.11.3.3 Storage Material and Equipment)

Discussion: Facility procedures define the responsibility of the cognizant system engineer for ensuring the identification of spare parts and equipment. These responsibilities include: identifying equipment approval designators, ensuring that special documentation required with spares is procured; determining minimum and maximum stocking levels, periodically verifying that spares are still needed and meet current requirements, identifying shelf-life requirements, providing for in-storage preventive maintenance requirements, and reviewing and approving spare reorders. Site warehousing services issue and provide for storing and protecting the spare parts and equipment. In addition, Warehouse Services ensures that spare parts and equipment are maintained in the specified storage level environment, schedules in-storage preventive maintenance activities, and performs shelf-life activities to maintain the integrity of stored material. Al1 spares and equipment are segregated and/or tagged to identify their significance to safety. In addition, all parts procured for modifications are tagged and segregated in a separate staging area reserved for this purpose.

Improvement: Existing maintenance program practices satisfy the intent of the stated objective.

Retrieval and Issuance

Objective: An effective spare parts program is implemented, to include catalogs for parts, material, and equipment. (DOE 4330.4B CHAPTER II SEC.11.3.4 Retrieval and Issuance)

Discussion: The FFTF has a comprehensive spare parts program administered with the cooperation of the Maintenance and Engineering organizations. This system defines and implements procedures for: receiving and shipping, disbursing, material control, warehouse services, and job safety planning to ensure the 


$$
\text { HNF-SP-0839, Rev. } 02
$$

integrity of spares, material, and equipment. Material needed for work packages is ordered using a material request form or obtained from shop maintained stock. The required documentation is included in the final work packages to provide traceability, as applicable. In addition, material used in safety applications is maintained in controlled storage areas and has appropriate identification and certifications. Unused parts and materials are returned promptly at completion of work packages. Spare parts are returned to the Facility Spare Parts system, and usable material is turned over to the maintenance shop for future use when the need for this type of material may arise again.

Improvement: Existing maintenance program practices satisfy the intent of the stated objective. 
HNF-SP-0839, Rev. 02

\subsection{CONTROL AND CALIBRATION OF MEASURING AND TEST EQUIPHENT}

The program for control and calibration of measuring and test equipment (M\&TE) should be consistent with the Quality Assurance requirements of DOE $5700.6 \mathrm{C}$ (1991) and ensure the accurate performance of facility instrumentation and equipment for testing, calibration, and repairs.

\section{Identification}

Objective: Each piece of M\&TE is assigned unique identification number, for identifying, tracing, and controlling. (DOE 4330.4B CHAPTER II SEC.12.3.1 Identification)

Discussion: A11 M\&TE at FFTF is identified by a unique number issued by the Calibration Laboratory. These numbers are traceable through a computer database, which allows the generation of a complete list of all M\&TE. Copies of the computer data files are maintained in two separate locations.

Improvement: Existing maintenance program practices satisfy the intent of the stated objective.

\section{Calibration}

Objective:

Calibration Standards are traceable to the National Institute of Standards and Technology (NIST) or other nationally recognized standards. Calibration of equipment is performed by qualified technicians using a high "ratio of accuracy" approved procedure. (DOE 4330.4B CHAPTER II SEC.12.3.2 Calibration)

Discussion: The M\&TE is calibrated at a calibration laboratory by qualified technicians, using methods and standards traceable to the NIST. Calibration frequency is determined by the manufacturer's recommendations and M\&TE use and reliability. The calibration history of each piece of M\&TE is evaluated regularly.

Improvement: Existing maintenance program practices satisfy the intent of the stated objective.

\section{Contro]}

Objective: Calibration standards are stored to assure equjpment is protected from damage, readily retrievable, and properly maintained. Controls are in place for the storing and checking of uncalibrated testing equipment. Calibration standards with limitations are clearly marked or tagged. Special protection and storage is given to equipment subject to radioactive contamination. (DOE 4330.4B CHAPTER II SEC.12.3.3 Control)

Discussion: A11 M\&TE at FFTF is stored in a controlled environment. All M\&TE is clearly labeled with a calibration sticker or a 7 imited calibration sticker if necessary. If a limited calibration 
HNF-SP-0839, Rev. 02

sticker is used, the calibration limits are clearly marked on the sticker or the calibration report is attached. The computer database ensures that items due are not issued unless authorized. M\&TE potentially subject to radioactive contamination is packaged to minimize contamination.

Improvement: Existing maintenance program practices satisfy the intent of the stated objective.

\section{Evaluation}

Objective: Calibration records are retrievable when equipment is found to be out of calibration or defective. Performance trending is in place to identify needed corrections or changes to M\&TE procedures. (DOE 4330.4B CHAPTER II SEC.12.3.4 Evaluation)

Discussion: Each piece of M\&TE is evaluated annually to determine if reliability is declining. The tool crib database has the ability to trend the calibration history of each item. If an item is found to be out of calibration, a list of jobs that item was checked out to be used on is sent to support personnel for evaluation.

Improvement: Existing maintenance program practices satisfy the intent of the stated objective. 
HNF-SP-0839, Rev. 02

\subsection{MAINTENANCE TOOLS AND EQUIPMENT CONTROL}

Methods should be established to provide for storage, issuance, and maintenance of an adequate and readily available supply of tools and equipment and also for the development of special tools and equipment needed in the maintenance program.

\section{Storage and Issuance}

Objective: Procedure for tool control is in place. (DOE 4330.4B CHAPTER II SEC.13.3.1 Storage and Issuance)

Discussion: Facility maintenance administration procedures define a tool control program with clear lines of responsibility. Tools available for loan, special equipment, and calibrated devices are stored and issued from a controlled tool crib using a computerized inventory and calibration tracking system.

Improvement: Existing maintenance program practices satisfy the intent of the stated objective.

\section{Tool and Equipment Maintenance}

Objective: Preventive Maintenance procedures are in place for maintenance tools and other support equipment. (DOE 4330.4B CHAPTER II SEC.13.3.2 Tool and Equipment Maintenance)

Discussion: Facility maintenance administration procedures clearly define a shop equipment and tool preventive maintenance program that uses a computerized recall system to ensure performance of required maintenance.

Improvement: Existing maintenance program practices satisfy the intent of the stated objective.

Use of Special Tools and Equipment

Objective: Procedures or special instructions are in $p l a c e$ for the use of special equipment or tools such as lifting equipment. (DOE 4330.4B CHAPTER II SEC.13.3.3 Use of Special Tools and Equipment)

Discussion: Rigging equipment and special tools are controlled by specific facility maintenance administrative procedures. This equipment is individually identified and each has well-specified requirements for serviceability, inspection, and use. The equipment is purchased or constructed under strict procedurat guidance with appropriate reviews and approvals, and is stored and issued from controlled facilities by knowledgeable attendants. 
HNF-SP-0839, Rev. 02

Improvement: Existing maintenance program practices satisfy the intent of the stated objective. 


$$
\text { HNF-SP-0839, Rev, } 02
$$

\subsection{FACILITY CONDITION INSPECTION}

Management should conduct periodic inspections of equipment and facilities to ensure excellent facility condition and housekeeping.

\section{Standards}

Objective: Managers and supervisors perform routine walk around inspections of equipment and facilities. (DOE 4330.4B CHAPTER II SEC.14.3.1 Standards)

Discussion: Policy and administrative procedures describe areas of responsibility for each of the various organizations and outline areas of responsibility for maintenance supervision. Facility inspections are being completed as required.

Improvement: Existing maintenance program practices satisfy the intent of the stated objective.

Training

Objective: Personnel involved in facility condition inspections are trained and knowledgeable of the standards expected by the facility manager. (DOE 4330.4B CHAPTER II SEC.14.3.2 Training)

Discussion: Procedures define areas of responsibility and required training for maintenance personnel involved in performing inspections.

Improvement: Existing maintenance program practices satisfy the intent of the stated objective.

\section{Procedures}

Objective: Administration procedures are in place that define the inspection program and expected standards. (DOE 4330.4B CHAPTER II SEC.14.3.3 Procedures)

Discussion: Administrative procedures are in place that cover the facility inspections and actions for correcting any deficiencies.

Improvement: Existing maintenance program practices satisfy the intent of the stated objective.

\section{Scope of Inspections}

Objective: Procedures clearly define the scope of inspections. (DOE 4330.4B CHAPTER II SEC.14.3.4 Scope of Inspections)

Discussion: Policy and administrative procedures define the requirements for inspections and define specific inspection criteria and scope. 
HNF-SP-0839, Rev. 02

Improvement: Existing maintenance program practices satisfy the intent of the stated objective.

\section{Inspection Program Elements}

Objective:. Inspection program includes list of facilities, specific areas within the facilities, and all personnel performing inspections. (DOE , 4330.4B CHAPTER II SEC.14.3.5 Inspection Program Elements)

Discussion: Administrative procedures define the scope of inspections for the facility, assign responsibility for the completion of the inspections, and establish tracking for inspection findings that require action.

Improvement: Existing maintenance program practices satisfy the intent of the stated objective.

\section{Reporting Deficiencies}

Objective: Deficiencies are reported and documented. (DOE 4330.4B CHAPTER II SEC.14.3.6 Reporting Deficiencies)

Discussion: Deficiencies are reported and documented using several systems in accordance with plant administrative procedures. A work request can be issued to track and document the deficiency. A computerized administrative system is in place for dealing specifically with audit, surveillance, and inspection findings and action items. Both tracking systems provide line management with action-item work packages to help focus attention on the completion of the items. The above systems provide the capability to deliver centralized reports for senior plant management assessments.

Improvement: Existing maintenance program practices satisfy the intent of the stated objective.

\section{Deficiency Followup}

Objective: Deficiencies are tracked for trending in the work control system or other corrective action system. (DOE 4330.4B CHAPTER II SEC.14.3.7 Deficiency Follow Up)

Discussion: Deficiencies are tracked by the Work Control System. A complete listing of all such items is maintained in a computer database that permits ready access and reporting. Line management is provided with action-item work packages to help focus attention on the completion of the action items. The system provides the capability to deliver centralized reports for senior plant management assessments.

Improvement: Existing maintenance program practices satisfy the intent of the stated objective. 


\subsection{MANAGEMENT INVOLVEMENT}

To ensure the safety of DOE nuclear facility operations, DOE and contractor corporate and facility managers should be sufficiently involved with facility operations to be technically informed and personally familiar with operations at the operating facility.

\section{Manager Involvement}

Objective: Managers and supervisors perform periodic walk throughs and become sufficiently involved and technically informed of operating condition within their facilities. (DOE $4330.4 \mathrm{~B}$ CHAPTER II SEC.15.3.1 Manager Involvement)

Discussion: Managers and supervisors are expected to spend time in the field observing and directing the work of crafts and support personnel. In addition, several formal facility walk through programs, such as the MOP and plant manager's facility housekeeping tour's are in place that ensure managers are involved with field activities regularly. Any observations or findings that result from these tours are formally published and tracked through the appropriate tracking system.

Improvement: Existing maintenance program practices satisfy the intent of the stated objective.

Performance Indicators, Goa]s, and Objectives Results

Objective: Management has developed maintenance indicators, goals, and objectives. (DOE 4330.4B CHAPTER II SEC.15.3.2 Performance Indicators, Goals, and Objectives ResuTts)

Discussion: Appropriate and meaningful performance indicators and goals are developed and published by facility management. Progress toward facility maintenance goals is tracked and reported. This information is then used to develop maintenance activity plans and identify areas where improvements can be made.

Improvement: Existing maintenance program practices satisfy the intent of the stated objective.

Feedback

Objective: Management has established a feedback system to promote modifications and improvements to the facility, and have the ability to apply lessons learned. (DOE $4330.4 B$ CHAPTER II SEC.15.3.3 Feedback)

A11 managers and supervisors have an "open door" policy and work to remain accessible to all individuals in the organization. Several formal programs are available to provide feedback to 
HNF-SP-0839, Rev. 02

management in addition to performance appraisal and counseling reviews.

The operational and maintenance experiences from the Hanford Site, Institute of Nuclear Power Operations (INP0), and the other reporting systems are reviewed; applicable information is disseminated to the appropriate organizations for review of lessons learned.

Improvement: Existing maintenance program practices satisfy the intent of the stated objective.

\section{Program Reviews}

Objective: Evaluation of each maintenance program element is periodically performed to assess facility equipment and systems, and the ability of craftsmen to perform high quality maintenance. Management periodically reviews training records of all maintenance personnel. (DOE 4330.4B CHAPTER II SEC.15.3.4 Program Reviews)

Discussion: Periodic reviews are performed of the various maintenance program elements as required in the facility maintenance plans and as called for in the plant and maintenance organizational procedures. Performance reviews and assessments are performed as required. Investigations and self-assessments are conducted by teams from across the plant and management organization to ensure as broad an assessment as possible. The findings and observations of these reviews are published and required actions are assigned and tracked by the plant action-item tracking system.

Improvement: Existing maintenance program practices satisfy the intent of the stated objective. 


\subsection{MAINTENANCE HISTORY}

A maintenance history and trending program should be maintained to document data, provide historical information for maintenance planning, and support maintenance and performance trending of facility systems and components.

Program Development

\section{A. Equipment Identification}

Objective: The maintenance history program should clearly define the systems and equipment that require documentation and retention of historical data. (DOE 4330.4B CHAPTER II SEC.16.3.1a Equipment Identification)

Discussion: A computer system provides an equipment and system listing that is easily cross-referenced to unique identification numbers, vendor nameplate information, drawings, and other common crossreferences. The PM and Instrument Calibration database is used in conjunction with this database to supply set points, vendor and spare parts information, and lubrication data. Ali work activities related to these components are part of the maintenance history program; historical records related to plant equipment are retained for the life of the plant.

Improvement: Existing maintenance program practices satisfy the intent of the stated objective.

B. Data Identification

Objective: The maintenance history program defines the type of data that should be collected and recorded. (DOE 4330.4B CHAPTER II SEC.16.3.Ib Data Identification)

Discussion: The retention data are identified and retained for the life of the plant or component. In addition, all PM and instrument calibration data are retained for the life of the plant or component. Data collected include corrective and preventive maintenance history records, modification records, vendor repair information, surveillance test procedure performance and test data, and specific calibration data.

Improvement: Existing maintenance program practices satisfy the intent of the stated objective.

\section{Data Collection}

0bjective: Data on systems and equipment that have been selected for history retention should be sent to the person or group responsible for maintenance history retention and applicable 


$$
\text { HNF-SP-0839, Rev. } 02
$$

data should then be entered in the maintenance history program. Any apparent errors, inconsistencies, or lack of detail should be referred back to the maintenance supervisor or another appropriate supervisor for resolution. (DOE 4330.4B CHAPTER II SEC.16.3.2 Data Collection)

Discussion: Al1 completed work documents, including corrective maintenance, PM and instrument calibration, surveillance and comṕliance procedures, and plant modifications, are returned to FFTF Work Control for post-work review. Any apparent errors or inconsistencies are resolved at this point with the appropriate maintenance, operations, or engineering personnel and then forwarded to the knowledgeable clerical personnel for data entry and retention. Packages are post-reviewed for adequacy and trending analysis by cognizant system and component engineers before final closeout.

Improvement: Existing maintenance program practices satisfy the intent of the stated objective.

Program Use

objective: Maintenance history data should be readily available for use by all organizations, especially the maintenance and technical support organizations. If maintenance history is computerized, users should be trained to access and manipulate the history databases. (DOE 4330.4B CHAPTER II SEC.16.3.3 Program Use)

Discussion: Maintenance history is available to all plant technical support personnel and maintenance $\mathrm{planners,} \mathrm{schedulers,} \mathrm{and} \mathrm{supervisors}$ via computerized databases and by retrieval of the work package or procedure that is retained for the life of the plant or component. In support of this program, training is provided to selected individuals on database administration and controt. Al1 work packages, including preventive and corrective maintenance, instrument calibration, surveillance procedures, and $p l a n t$ modification and test procedures, are reviewed by Operations 7 ine management or senior operations personnel before closeout. In addition, these work documents are reviewed by work control personnel and cognizant system engineering. The cognizant system or component engineers manualiy perform trending analysis of selected equipment based on the importance of the equipment to safety or plant operation. Maintenance history analysis is routinely used to support equipment failure analysis, identify equipment requiring rework, preventive maintenance program justification, budget preparations, ALARA management, identify maintenance program improvements, and assist in plant life extension studies.

Improvement: Existing maintenance program practices satisfy the intent of the stated objective. 
HNF-SP-0839, Rev. 02

\subsection{ANALYSIS OF MAINTENANCE PROBLEMS}

Systematic analysis should be used to determine and correct root causes of unplanned occurrences related to maintenance.

\section{Information Collection}

objective: Operator logs and records, computer records, interviews, and personnel statements are collected for all unplanned occurrences. (DOE 4330.4B CHAPTER II SEC.17.3.1 Information Collection)

Discussion: A systematic analysis of unplanned occurrences is performed in accordance with plant, Site, and DOE procedures and orders. Information to support the analys is of the event is collected through interviews with the personnel involved; detailed operations logs; instrument readings, and walkdowns conducted by an independent evaluator. Detailed information on the reactor core can also be obtained, if desired, from automated data collection systems. Other information is gathered by the evaluator based on the event reported.

Improvement: Existing maintenance program practices satisfy the intent of the stated objective.

Event Analys is

Objective: Systematic analysis is performed to reconstruct unplanned occurrence. (DOE 4330.4B CHAPTER II SEC.17.3.2 Event Analysis)

Discussion: The procedures direct the evaluator to examine causal factors in the following areas: equipment/material problems, procedure problems, personnel errors, design problems, training deficiencies, management problems, and external phenomena. once causal factors are identified, the evaluator is directed to select one root cause and up to three contributing causes.

Improvement: Existing maintenance program practices satjsfy the intent of the stated objective.

\section{Cause Determination}

Objective: Actual or probable causes of problems are evaluated to establish a final root cause. (DOE 4330.4B CHAPTER II SEC.17.3.3 Cause Determination)

Discussion: Root cause analysis procedures establish the requirements to review and evaluate occurrences to ensure that the significance, root causes, and generic implications are identified. The cause of each occurrence must be thoroughly addressed as the information to evaluate it becomes available. The final evaluation must include a complete consideration of the cause 
HNF-SP-0839, Rev. 02

and contributory factors, and provide analys is to show what causes were root to the occurrence and what were only contributory. Any commonly accepted method of root-cause analysis may be used to evaluate the occurrence.

Improvement: Existing maintenance program practices satisfy the intent of the stated objective.

\section{Corrective Action}

Objective: Corrective action plans are developed, executed, and tracked to completion. (DOE 4330.4B CHAPTER II SEC.17.3.4 Corrective Action)

Discussion: Once the causes are identified, corrective actions are developed to correct them. Individual action items are assigned to appropriate managers for resolution, and entered into a database for commitment monitoring.

Improvement: Existing maintenance program practices satisfy the intent of the stated objective.

\section{Corrective Action Follow-up}

Objective: Post-maintenance testing is performed to determine if additional maintenance work or fact finding will be required. (DOE $4330.4 \mathrm{~B}$ CHAPTER II SEC.17.3.5 Corrective Action Followup)

Discussion: Quality Assurance is responsible for verifying the closeout of all final-occurrence-report corrective-action items resulting from emergencies or unusual occurrences. Additionally, other affected oversight organizations are responsible for verifying that the corrective-action items in their area of responsibility have been completed, and that the corrective actions are adequate to correct the root causes identified.

Improvement: Existing maintenance program practices satisfy the intent of the stated objective.

Generic Follow-up

Objective: The analysis program should address any generic corrective actions needed to be taken after problems with one piece of equipment have been determined and corrected. (DOE 4330.4B CHAPTER II SEC.17.3.6 Generic Followup)

Discussion: Part of the evaluation of an occurrence includes a review for generic impacts. Action items are generated, where appropriate, to evaluate similar equipment or procedures for potential problems based on the reported occurrence. 
HNF-SP-0839, Rev. 02

Improvement: Existing maintenance program practices satisfy the intent of the stated objective. 
HNF-SP-0839, Rev. 02

\subsection{MODIFICATION WORK}

Facility modification work, including temporary modifications, should be accomplished under the same administrative controls as those applied to the facility maintenance activities so that risk to facility equipment, environment, or personnel is not increased because of the modification work.

\section{Maintenance Program Interface With Modifications}

Objective: Maintenance program includes control procedures for facility structure, system, or component modifications. (DOE $4330.4 \mathrm{~B}$ CHAPTER II SEC.18.3.1 Maintenance Program Interface with Modifications)

Discussion: Modification work, permanent and temporary, is accomplished using the same administrative procedures and guidelines with in the work control process. Modification work packages are reviewed before implementation. for changes to drawings, procedures, and spare parts and vendor information. Ail required changes must be implemented before modification work package completion and subsequent return of equipment to normal plant operation. Plant modifications are reviewed to ensure that future preventive maintenance and predictive maintenance programs are modified accordingly. All modifications, including temporary modifications, are reviewed for Unresolved Safety Questions before plant modification.

Improvement: Existing maintenance program practices satisfy the intent of the stated objective.

\section{Temporary Repairs or Temporary Modjfications}

Objective: Procedures are in place to assure permanent corrective action is taken, whenever temporary repairs have been made to allow equipment/systems to remain in service. (DOE 4330.4B CHAPTER II SEC.18.3.2 Temporary Repairs/Temporary Modifications)

Discussion: Temporary modifications receive the same overview as permanent modifications. Temporary modifications are periodically reviewed and evaluated.

Improvement: Existing maintenance program practices satisfy the intent of the stated objective. 
HNF-SP-0839, Rev. 02

\subsection{ADDITIONAL MAINTENANCE MANAGEMENT REQUIREMENTS}

\section{Seasonal Facility Preservation Requirements}

Objective: A program should be in place to prevent equipment and building damage due to cold weather at any nuclear facility that may be at risk. This program should include the preparation of a freeze protection plan which includes details on inspections, preventive maintenance, and corrective maintenance imposed on nuclear facility equipment and buildings to assure continued safe facility operations. (DOE 4330.4B CHAPTER II SEC:19.1 Seasonal Facility Preservation Requirements)

Discussion: A detailed review of plant facilities and systems has been performed and those actions that are required to protect these assets from seasonal damage (such as freeze protection) have been determined. The required actions are formalized in an approved plant administrative procedure that is implemented automatically by the Operations scheduTing tickle-file system. The procedure includes plans to both implement and suspend those measures that were determined to be necessary to protect facilities and systems from seasonal damage.

Improvement: Existing maintenance program practices satisfy the intent of the stated objective. 
HNF-SP-0839, Rev. 02

This page intentionally left blank. 
HNF-SP-0839, Rev. 02

\subsection{DEVIATIONS REQUESTED WITH SUPPORTING RATIONALE}

No deviations from the requirements of DOE $4330.4 B$ are requested at this. time. 
HNF-SP-0839, Rev. 02

This page intentionally left blank. 
HNF-SP-0839, Rev. 02

\subsection{SELF-ASSESSHENT SCHEDULE}

FFTF MAINTENANCE

SELF-ASSESSMENT

BIENNIAL. SCHEDULE

\begin{tabular}{|c|c|c|c|c|c|c|c|c|}
\hline \multirow{2}{*}{$\begin{array}{l}\text { CONDUCT OF MAINTENANCE } \\
\text { NUCLEAR FACILITIES } \\
\text { DOE } 4330.4 B\end{array}$} & \multicolumn{4}{|c|}{ CY $19 X X$} & \multicolumn{4}{|c|}{ CY $19 X X$} \\
\hline & 1 st & 2nd & $3 r d$ & 4 th & 1 st & 2nd & $3 r d$ & $4 \mathrm{th}$ \\
\hline 2. Organization and Administration & $x$ & & & & & & & \\
\hline 3. Training and Qualification & & & $x$ & & & & & \\
\hline 4. Facilities, Equipment and Tools & $x$ & & & & & & & \\
\hline 5. Types of Maintenance & & $x$ & & & & & & \\
\hline 6. Maintenance Procedures & & & $x$ & & & & & \\
\hline 7. Planning and Scheduling & & & & $x$ & & & & \\
\hline 8. Control of Activities & & & & $x$ & & & & \\
\hline 9. Post-Maintenance Testing & & $\mathrm{x}$ & & & & & & \\
\hline 10. Procurement of Materials & & & & & & & $x$ & \\
\hline 11. Material Receipt and Handling & & & & & & & $x$ & \\
\hline 12. Control of Test Equipment & & & & & $x$ & & & \\
\hline 13. Toots and Equipment Control & & & & & $x$ & & & \\
\hline 14. Facility Condition Inspection & $x$ & & & & & & & \\
\hline 15. Management Involvement & & & & & & $x$ & & \\
\hline 16. Maintenance History & & & & & & & & $x$ \\
\hline 17. Analysis of Problems & & & & & & & & $\mathrm{x}$ \\
\hline 18. Modification Work & & $x$ & & & & & & \\
\hline 19. Additional Management Requirements & & & & & & $x$ & & \\
\hline
\end{tabular}


HNF-SP-0839, Rev. 02

This page intentionally left blank.

$6-2$ 


$$
\text { HNF-SP-0839, Rev. } 02
$$

\subsection{REFERENCES}

DOE $4330.4 \mathrm{~B}$

DOE $4580.18 \mathrm{~B}$

DOE $5480.20 \mathrm{~A}$

DOE $5700.6 \mathrm{C}$

DOE-RL-92-36

HSRCM-1

WHC-CM-1

WHC-CM-1-3

WHC-CM-1-4

WHC-CM-1-5

WHC-CM-1-8

WHC-CM-2-1

WHC-CM-2-2

WHC-CM-2-3

HHC-CM-2-1

WHC-CM-3-5

WHC-CM-3-6

WHC-CM-4-2

WHC-CM-6-1

WHC-CM-6-14

WHC-CM-6-27

WHC-CM-8-7

WHC-IP-0759

WHC-IP-1026

WHC-SP-0329

HNF-SP-0839

WHC-SP-0446

WHC-SP-0866

WHC-TI-75002
(1994) Maintenance Management Program

(1994) Nuclear Facility Training Accreditation Program

(1994) Personnel Selection, Qualification, and Training Requirements for DOE Nuclear Facilities

(1991) Quality Assurance

DOE-RL Hanford Site Hoisting and Rigging Manual

Hanford Site Radiological Control Manual

Company Policies and Charters

Management Requirements and Procedures

Corrective Action Management Manual

Standard Operating Practices

Work Management Manual

Procurement Manual and Procedures

Materials Management Manual

Property Management Manual

Training Standards

Document Control and Record Management Manual

Uniform Publications System

Quality Assurance Manual

Standard Engineering Practices

FFTF Plant Policy Manual

FFTF Engineering Instructions

Operations Support Services

FFTF/FMEF Maintenance Administration Procedures Manual

Engineering Practice Guidelines

400 Area Training Plans

Maintenance Implementation Plan for the Fast Flux Test Facility

Physical and Electrical Standards Laboratory General Operating Procedures

Westinghouse Hanford Conduct of Maintenance Manual

Fast Flux Test Facility Final Safety Analysis Report (FSAR)

\section{FFTF Operating Procedure:}

A-2

A-3

A-5

A-10

A-28

A-32

A-37

A-41

A-42

A-43

A-44
Job Control System - Automated Data Processing (JCS-ADP) Instructions Operations Organization and Responsibilities

FFTF Procedure Administration Watchstander Practices Work Authorization Using Job Control System - Automated Data Processing (JCS-ADP)

Protective Maintenance System

Fast Flux Test Facility Corrective Action Management System Administration of the Human Performance Enhancement System FFTF Plant Cold Weather Protection Program Administration FFIF Plant Shutdown Documentation Administration FFTF Occurrence Management Procedure 


$$
\text { HNF-SP-0839, Rev. } 02
$$

FFTF Operations Guide:

$$
\begin{array}{ll}
\text { G-001 } & \text { Procedure Writer's Guide } \\
\text { G-003 } & \text { Procedure Processing Guide } \\
\text { FFTF Plant ALARA Guide }
\end{array}
$$

FFTF Operations Procedure:

$$
\begin{aligned}
& \text { SI -12-95 Operation of the Freeze Protection System } \\
& \text { SI -21-2 }
\end{aligned}
$$

MASF Operations Procedure:

MN-26-2 MASF Safety Equipment Inspections

Other Facility Reference Manuals:

Maintenance Work Procedure's (MWP)

Operation and Maintenance Manual's (OMM).

$7-2$ 
HNF-SP-0839, Rev. 02

DISTRIBUTION

Number of copies

ONSITE

4

U. S. Department of Energy-

Richland Field office

K. A'. Benguiat

R3-78

T. H. Davies

R3-78

0 . A. Farabee

R3-79

R. G. Hastings

R3-78

5

B\&W Hanford Company

G. J. Boehnke

N1-88

J. A. Boyd

M. F. Duffield

N1-86

H. F. Heer

N1-88

E. F. Loika

H5-31

N2-51

3

other

Central Files

A3-88

Document Processing Center

A3-94

Document Processing and

Distribution

A3-89 
HNF-SP-0839, Rev. 02

This page intentionally left blank.

Distr-2 